\title{
Respiratory Tract Infections in Children in the Commu- nity: Prospective Online Inception Cohort Study
}

\author{
Alastair D. Hay, FRCGP $P^{1,3}$ \\ Emma Anderson, DHealthPsy ${ }^{2,3}$ \\ Sue Ingle, $\mathrm{PbD}^{3,4}$ \\ Charles Beck, $P b D^{3,5}$ \\ William Hollingworth, $\mathrm{PbD}^{4}$ \\ ${ }^{1}$ Centre for Academic Primary Care, \\ Bristol Medical School: Population Health \\ Sciences, University of Bristol, Bristol, \\ United Kingdom \\ ${ }^{2}$ Centre for Child and Adolescent Health, \\ Bristol Medical School: Population Health \\ Sciences, University of Bristol, Bristol, \\ United Kingdom \\ ${ }^{3}$ NIHR Health Protection Research Unit in \\ Evaluation of Interventions, University of \\ Bristol, Bristol, United Kingdom \\ ${ }^{4}$ Bristol Medical School: Population Health \\ Sciences, University of Bristol, Bristol, \\ United Kingdom \\ ${ }^{5}$ Field Epidemiology Service, Public Health \\ England, Bristol, United Kingdom
}

Conflicts of interest: authors report none.

\section{CORRESPONDING AUTHOR}

Alastair D. Hay, FRCGP

Centre for Academic Primary Care

Bristol Medical School: Population Health

Sciences

University of Bristol, Canynge Hall

39 Whatley Road

Bristol, BS8 2PS, UK

alastair.hay@bristol.ac.uk

\begin{abstract}
PURPOSE Describe the duration of symptoms, proportion of parents seeking primary care consultations, and costs for respiratory tract infections (RTIs) of children in the community.

METHODS Community-based, online, prospective inception cohort study. General practitioners from socioeconomically diverse practices posted study invitations to parents of 10,310 children aged $\geq 3$ months and $<15$ years.

RESULTS One parent of 485 (4.7\%) children in 331 families consented, completed baseline data and symptom diaries, and agreed to medical record review. Compared with nonresponders, responding parent's children were younger (aged 4 vs 6 years) and less socioeconomically deprived. Between February and July 2016, 206 parents reported 346 new RTIs in 259 children. Among the 197 first RTIs reported per family, it took 23 days for $90 \%$ (95\% Cl, 85\%-94\%) of children to recover. Median symptom duration was longer: in children with primary care consultations ( 9 days) vs those without consultations ( 6 days, $P=0.06$ ); children aged $<3$ years ( 11 days) vs $>3$ years ( 7 days, $P<.01$ ); and among children with reported lower RTI symptoms ( 12 days) vs those with only upper RTI symptoms (8 days, $P<.001)$. Sixteen (8.1\%; 95\% Cl, 4.7\%-12.8\%) of 197 children had primary care consultations at least once (total 19 consultations), and a similar proportion had time off school or nursery. Sixty of $188(32 \% ; 95 \% \mathrm{Cl}$, 25\%-39\%) parents reported paying for medications for their child's illness.
\end{abstract}

CONCLUSIONS Parents can be advised that RTI symptoms last up to 3 weeks. Policy makers should be aware that parents may seek primary care support in at least 1 in 12 illnesses.

Ann Fam Med 2019;17:14-22. https://doi.org/10.1370/afm.2327.

\section{INTRODUCTION}

$\mathrm{S}$ elf care is central to sustainable primary care. ${ }^{1,2}$ Accurate knowledge regarding respiratory tract infection (RTI) symptoms and their duration is an essential part of self care, ${ }^{3}$ and supports patients in knowing when they should seek help. ${ }^{4}$ A recent systematic review ${ }^{5}$ estimated children's RTI duration using 48 studies, but the majority of studies were conducted in a consulting population whose illness characteristics are likely to differ from the nonconsulting population.

Policy makers currently measure primary care antibiotic prescribing as the absolute number of prescriptions issued ${ }^{6}$ or, where diagnostic codes are reliable, as a percentage of infection consultations. ${ }^{7}$ Neither measure is sensitive, however, to the number of people falling ill, who might require primary care and antibiotic treatment. To fully understand changes in antibiotic prescribing, measures of 3 elements are required: the number of people falling $\mathrm{ill}_{;}$the proportion of these choosing to consult primary care; and the proportion of these who are prescribed an antibiotic. The first and second elements cannot be measured using currently available clinical data sets, and would require customized data collection mechanisms.

We aimed to demonstrate the feasibility of measuring the first and second elements using online methods-to recruit and follow a cohort 
of children in the community as they developed RTIs The feasibility results (including microbiological elements and a qualitative evaluation) will be reported elsewhere, but since demonstrating feasibility required the recruitment of a few hundred families, the present paper reports our findings on 3 study objectives: (1) to estimate the duration of RTI symptoms in children in the community ${ }_{i}(2)$ to estimate the proportion of parents seeking primary care help when their child develops an RTI; and (3) to estimate the costs of RTIs to families (since costs of RTIs have only been estimated in consulting populations). ${ }^{8}$

\section{METHODS}

\section{Design, Setting, and Participant Recruitment}

This was a community-based, online, prospective inception cohort study. Recruitment methods are described in detail elsewhere. ${ }^{9}$ Briefly, general physician (GP) practices serving a broad range of socioeconomic populations within 10 miles of Bristol, United Kingdom, were invited to express interest via the National Institute of Health Research Clinical Research Network. Participating practices identified children aged $\geq 3$ months and $<15$ years and using medical record diagnostic codes, excluding immunecompromised children, and those with terminal illnesses. The practices sent all parents/caregivers (from here on referred to as parents) of remaining children a study information sheet, invitation letter, consent form, and (for children aged $>7$ years) a child-friendly information sheet and assent form. Study paperwork mailings were staggered between February 26, 2016 and July 1, 2016 to prevent study team overload.

\section{Baseline and Follow-Up Data Collection}

One parent per household returned signed consent (and assent) forms to the study team using prepaid envelopes. On receipt, the study team telephoned the parent to confirm eligibility and provide instructions regarding baseline data completion online (including parent and household demographics), at which point the child was enrolled. Parents of children with RTI symptoms at enrollment were advised to report when that illness resolved and were invited to start the study processes at the onset of the next illness.

The study database generated weekly parent e-mails/texts requesting parents to respond with a yes or no to the query asking if their child had developed new RTI symptoms (blocked/runny nose; earache/ ear discharge; sore throat; cough $_{i}$ chesty symptoms [breathing faster than normal; wheeze or whistling chest]). A negative response resulted in no further action. With a positive response, parents were invited to post online each day the presence and severity of the above symptoms, along with the constitutional symptoms (fever/chills, fatigue, disruption to sleep, and disruption to other usual activities). Symptom severity was scored using a validated ${ }^{10}$ Likert scale format: 0 (normal or no problem) to 6 (as bad as it could be). To minimize respondent burden, parents were invited to report the presence and severity of the same symptoms on a weekly basis for RTI episodes lasting more than 21 days. Data were collected on new (parent-reported) RTI symptoms starting before July 31, 2016 and all children were followed until symptom resolution.

At the end of each week of symptoms (or on confirmation of symptom resolution), parents were asked to report whether the child had been kept out of school/ nursery, if the parent took time off work due to the RTI, and to provide the number of days of school/nursery or hours of work missed. Parents were also asked to report how much they spent on medications. Primary care consultations (including telephone calls and emergency department visits) and antibiotic prescriptions were recorded by review of the child's primary care notes.

\section{Statistical Methods}

\section{Sample Size Calculation}

There is little existing evidence to inform a pediatric study of consultation rates. Recent UK survey data suggest around $20 \%$ of adults with RTI in the community consult. ${ }^{11}$ With 300 RTI episodes, we would have $\pm 5 \%$ precision around a $20 \%$ point estimate for consultation rates $(95 \% \mathrm{CI}, 15 \%-25 \%)$, using the exact binomial calculation. For symptom duration, using 300 RTI episodes, would have $\pm 3 \%$ precision around the $90 \%$ point for children recovered (95\% CI, 87\%-93\%). The time taken for $90 \%$ of children to recover was considered the most useful cut-point in previous studies. ${ }^{5,12}$

\section{Derivation of Variables}

Duration of RTI was calculated as the time from the first through last days that any symptom was reported (preceding 2 consecutive symptom-free days). For RTI episodes lasting more than 21 days we calculated the end date as the midpoint between potential minimum and maximum end dates. Respiratory tract infections were categorized as being either an upper RTI when only earache, sore throat, runny/blocked nose, ear discharge, dry cough or barking/croupy cough were reported, or as lower RTI when wet/productive cough, breathing faster/shortness of breath, or wheeze/whistling chest were also present.

\section{Data Analyses}

All analyses were performed using Stata version 14.1 (StataCorp LLC). Main analyses were restricted 
to the first RTI occurring within families to avoid within-family and within-child clustering. The duration of each RTI episode was treated as a survival outcome. Where symptom resolution was not reported, time analyses were censored on the last known symptomatic day. Median duration of RTI was estimated, as were 10 th, 25 th, 75 th, and 90 th percentiles. Symptom duration was stratified according to whether the parent attended primary care with the child and whether any lower RTI symptoms were reported. Finally, the impact of upper vs lower RTI status on constitutional symptoms was investigated by calculating the mean of the maximum constitutional symptom scores by RTI type. Percentages were used to describe primary care consultation behavior between the illness start and end dates.

\section{Effects of Sample Generalizability on Symptom Duration and the Proportion Consulting}

As the final analytic sample was relatively young and less socioeconomically deprived in comparison to invited children, ${ }^{13}$ we investigated how measures of age and deprivation (using the Index of Multiple Deprivation $^{14}$ and parent education) affected RTI duration and consultation behavior. The log-rank test for equality of survivor functions was used to assess if these explanatory variables influenced duration as a survival outcome. We also assessed whether parent or child-level baseline characteristics were associated with consultation using $\chi^{2}$ tests for categorical variables and Wilcoxon rank-sum tests for continuous variables.

\section{Sensitivity Analyses}

These assessed the stability of symptom duration estimates to within-family and within-child clustering by, respectively, using data from the first RTI per child and all RTIs.

\section{RESULTS}

\section{Practice and Child Recruitment}

Fifty-four GP practices were invited, 19 practices expressed interest, of those, 10 agreed to participate, and 5 were selected for socioeconomic diversity. Each practice sent invitations in a single batch, the first during the week ending February 26, 2016, and the second to fifth batches during the weeks ending March 4, March 11, April 15, and May 20, 2016. A total of 10,310 invitations were sent, with 331 parents ( 1 per household) consenting and completing baseline data for 485 enrolled children (Figure 1). The number enrolled from the 5 practices were 175, 140, 76, 51, and 43. The number of children enrolled by month were 17 in February, 103 in March, 114 in April, 165 in May, 85 in June, and 1 in July.

Compared with children whose parents did not respond, enrolled children were younger (median aged 4 vs 6 years) and less socioeconomically deprived (Supplemental Table 1, available at http://www. AnnFamMed.org/content/17/1/14/suppl/DC1/). During follow-up (to July 31, 2016), 206 parents (1 per household) reported 346 new RTI episodes, in 259 children. Parents reported 187 children had 1 RTI, 75 children had 2, and 15 children had 3 RTIs.

\section{Description of Children and Families}

Two hundred six families reported first RTI episodes. The median age of parents was 38 years, 94\% were female, $88 \%$ reported ethnicity as white, and $74 \%$ were in full or part-time employment (Table 1). Most parents $(86 \%)$ had undergraduate or postgraduate degrees, and $20 \%$ reported medical or nursing training. Symptom diaries had illness start dates recorded by 197 (96\%) families, and illness end dates recorded by 180 (87\%) families. Aside from education level, there was no evidence of differences in parent characteristics between those fully completing and those not starting the symptom diaries (Table 1). Similarly, there was no evidence of differences in children's characteristics (Table 1): median age 3 years, $55 \%$ were female, $89 \%$ white, $9 \%$ had asthma, and $59 \%$ had 1 or more siblings.

\section{Symptom Duration and Severity}

Survival analyses were restricted to the 197 first RTI episodes with a start date recorded. Median RTI duration was 9 days (interquartile range 7-14 days) and it took 23 days for $90 \%$ (95\% CI, 85\%-94\%) of children to recover (Table 2, Figure 2). There was modest evidence that RTI duration differed between children with consultations and those without, having medians of 13 and 9 days, respectively, $P=.06$ (Table 2).

Parents reported exclusively upper RTI symptoms in $86(45 \%)$ children and 1 or more lower RTI symptoms in 104 (55\%) children. There was strong evidence that illnesses with lower RTI symptoms were associated with longer duration compared with those having exclusively upper RTI symptoms, with medians of 12 and 8 days, respectively, $P<.001$ (Table 2). Parental reporting of lower RTI symptoms was associated with a doubling of mean maximum constitutional symptom scores compared with upper RTI (Table 2). Mean symptom severity for children with exclusively upper RTI symptoms showed runny nose to be the most persistently severe symptom while earache was the fastest to resolve (Supplemental Figure 1, available at http://www.AnnFamMed.org/content/17/1/14/suppl/ DC1/). For children with at least 1 lower RTI symp- 
tom, all symptoms persisted for 3 weeks with runny nose and wet cough being the most severe symptoms. (Supplemental Figures 2a and 2b, available at http:// www.AnnFamMed.org/content/17/1/14/suppl/DC1/).
School/Nursery Absences and Time Off Work

Seventeen of $188(9.0 \%$; $95 \%$ CI, 4.9\%-13.1\%)

responding parents reported a school/nursery absence during the first week of symptoms. The mean number

\section{Figure 1. Flow diagram of participant recruitment.}

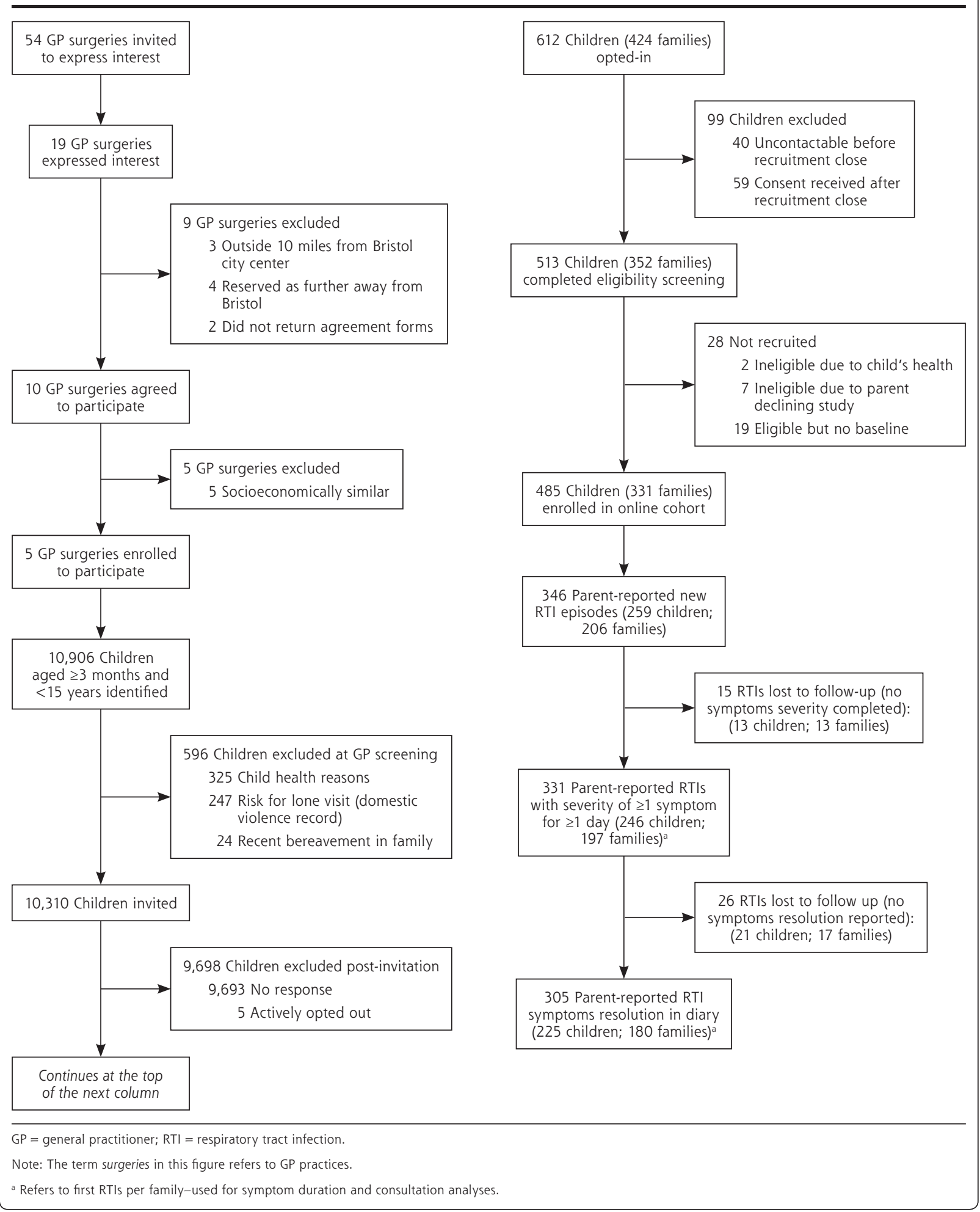


of days absent in the first week was 2.0 (range 0.5-5.0). Only 2 parents reported absences (totaling 1.5 days) after the first week. Five of $188(2.7 \%$; 95\% CI 0.3\%$5.0 \%)$ parents reported taking time off work during the first week, with a mean of 14.8 (range 4.0-24.0) hours lost. One parent reported time off work (7.0 hours) after the first week.

\section{Primary Care Attendance}

Of the 197 first RTI episodes reported, primary care medical note reviews showed $16(8.1 \%$; 95\% CI, 4.7\%-12.8\%) resulted in at least 1 primary care consultation between illness start and end dates, of which 14 were face-toface GP consultations and 2 were emergency department attendances. Three of the primary care consultations resulted in an antibiotic prescription (all amoxicillin). There were no hospital admissions, and there were a total of 19 primary care consultations, equivalent to 9.6 consultations per 100 RTI episodes. Consultation rates per 100 symptomatic RTI illness weeks were: 5.1 in week 1, 4.0 in week 2, 5.3 in week 3, 5.3 in week 4 , none in week 5 , and 14.3 in week 6. Sixty of 188 (31.9\%; 95\% CI, 25.2\%-38.6\%) parents reported paying for new medications for their child's illness. For these parents, the mean amount spent over the course of the illness was US $\$ 8.12$ (range $\$ 1.42-\$ 55.50$ ).

\section{Effects of Sample Generaliz-} ability on Symptom Duration and the Proportion Consulting

Univariable analyses showed no evidence that maternal measures of deprivation or education were associated with either symptom duration or the proportion consulting (Table 3). There was evidence that younger children (aged $\leq 3$ years) had longer median duration illnesses (11 days) than older
Table 1. Baseline Characteristics of Parents, Children, and Households, According to Whether or Not Symptom End Dates Were Recorded, and Restricted to the First RTI Episodes in a Family $(n=206)$

\begin{tabular}{|c|c|c|c|}
\hline \multirow[b]{2}{*}{ Characteristics } & \multirow{2}{*}{$\begin{array}{l}\text { First RTI } \\
\text { Episodes } \\
(n=206)\end{array}$} & \multicolumn{2}{|c|}{$\begin{array}{c}\text { Symptom End Dates } \\
\text { Recorded? }\end{array}$} \\
\hline & & No $(n=26)$ & Yes $(n=180)$ \\
\hline \multicolumn{4}{|l|}{ Parents } \\
\hline \multicolumn{4}{|l|}{ Sex, No. (\%) } \\
\hline Missing & $2(0.97)$ & & \\
\hline Female & 193 (93.69) & $26(100.00)$ & $167(93.82)$ \\
\hline Male & $11(5.34)$ & $0(0.00)$ & $11(6.18)$ \\
\hline Age, median (IQR), y & $38(34-43)$ & $36(34-41)$ & $38(34-43)$ \\
\hline \multicolumn{4}{|l|}{ Ethnicity, No. (\%) } \\
\hline Missing & $9(4.37)$ & & \\
\hline Asian & $5(2.43)$ & $0(0.00)$ & $5(2.91)$ \\
\hline Black & $5(2.43)$ & $2(8.00)$ & $3(1.74)$ \\
\hline Mixed & $5(2.43)$ & $1(4.00)$ & $4(2.33)$ \\
\hline White & $182(88.35)$ & $22(88.00)$ & $160(93.02)$ \\
\hline \multicolumn{4}{|l|}{ Employment, No. (\%) } \\
\hline Missing & $9(4.37)$ & & \\
\hline Full-time parent/caregiver & $34(16.50)$ & $4(16.00)$ & $30(17.44)$ \\
\hline In full-time education & $2(0.97)$ & $0(0.00)$ & $2(1.16)$ \\
\hline Not currently employed & $8(3.88)$ & $2(8.00)$ & $6(3.49)$ \\
\hline Working full time & $41(19.90)$ & $7(28.00)$ & $34(19.77)$ \\
\hline Working part time & $112(54.37)$ & $12(48.00)$ & $100(58.14)$ \\
\hline \multicolumn{4}{|l|}{ Education, No. (\%) } \\
\hline Missing & $9(4.37)$ & & \\
\hline No official qualification & $2(0.97)$ & $0(0.00)$ & $2(1.16)$ \\
\hline Up to GCSEs/GCEs/O Levels or equivalent & $8(3.88)$ & $4(16.00)$ & $4(2.33)$ \\
\hline A Levels/NVQs/GNVQs or equivalent & $9(4.37)$ & $2(8.00)$ & $7(4.07)$ \\
\hline First degree/diploma/HNC/HND & $107(51.94)$ & $11(44.00)$ & $96(55.81)$ \\
\hline Higher degree (eg, MSc, PhD) & $71(34.47)$ & $8(32.00)$ & $63(36.63)$ \\
\hline \multicolumn{4}{|l|}{ Any medical/ nursing training, No. (\%) } \\
\hline Missing & $9(4.37)$ & & \\
\hline No & $155(75.24)$ & $22(88.00)$ & $133(77.33)$ \\
\hline Yes & $42(20.39)$ & $3(12.00)$ & $39(22.67)$ \\
\hline \multicolumn{4}{|l|}{ Children } \\
\hline Age, (median, IQR), y & $3(1-7)$ & $3(1-6)$ & $3(1-7)$ \\
\hline \multicolumn{4}{|l|}{ Sex, No. (\%) } \\
\hline Female & $114(55.34)$ & $15(57.69)$ & $99(55.00)$ \\
\hline Male & $92(44.66)$ & $11(42.31)$ & $81(45.00)$ \\
\hline \multicolumn{4}{|l|}{ Ethnicity, No. (\%) } \\
\hline Asian & $6(2.91)$ & $1(3.85)$ & $5(2.78)$ \\
\hline Black & $5(2.43)$ & $1(3.85)$ & $4(2.22)$ \\
\hline Mixed & $11(5.34)$ & $3(11.54)$ & $8(4.44)$ \\
\hline White & $184(89.32)$ & $21(80.77)$ & $163(90.56)$ \\
\hline \multicolumn{4}{|l|}{ Asthma, No. (\%) } \\
\hline No & $187(90.78)$ & $22(84.62)$ & $165(91.67)$ \\
\hline Yes & $19(9.22)$ & $4(15.38)$ & $15(8.33)$ \\
\hline \multicolumn{4}{|l|}{ Eczema, No. (\%) } \\
\hline No & $128(62.14)$ & $18(69.23)$ & $110(61.11)$ \\
\hline Yes & 78 (37.86) & $8(30.77)$ & $70(38.89)$ \\
\hline \multicolumn{4}{|l|}{ Hay fever, No. (\%) } \\
\hline No & $186(90.29)$ & $22(84.62)$ & 164 (91.11) \\
\hline Yes & $20(9.71)$ & $4(15.38)$ & $16(8.89)$ \\
\hline
\end{tabular}


Table 1. Baseline Characteristics of Parents, Children, and Households, According to Whether or Not Symptom End Dates Were Recorded, and Restricted to the First RTI Episodes in a Family $(n=206)$ (continued)

\begin{tabular}{|c|c|c|c|}
\hline \multirow[b]{2}{*}{ Characteristics } & \multirow{2}{*}{$\begin{array}{l}\text { First RTI } \\
\text { Episodes } \\
(\mathrm{n}=206)\end{array}$} & \multicolumn{2}{|c|}{$\begin{array}{l}\text { Symptom End Dates } \\
\text { Recorded? }\end{array}$} \\
\hline & & No $(n=26)$ & Yes $(n=180)$ \\
\hline \multicolumn{4}{|c|}{ Child receiving any breast milk at 3 months, No. (\%) } \\
\hline Don't know & $2(0.97)$ & $1(3.85)$ & $1(0.56)$ \\
\hline No & $30(14.56)$ & $4(15.38)$ & $26(14.44)$ \\
\hline Yes & $174(84.47)$ & $21(80.77)$ & $153(85.00)$ \\
\hline \multicolumn{4}{|l|}{ Child attending school, No. (\%) } \\
\hline No & $125(60.68)$ & $15(57.69)$ & $110(61.11)$ \\
\hline Yes & $81(39.32)$ & $11(42.31)$ & $70(38.89)$ \\
\hline \multicolumn{4}{|c|}{ Child (not in school) attending daycare regularly, No. (\%) } \\
\hline Not relevant (attends school) & 81 & & \\
\hline No & $36(28.80)$ & $6(40.00)$ & $30(27.27)$ \\
\hline Yes (1-2 days per week) & $50(40.00)$ & $6(40.00)$ & $44(40.00)$ \\
\hline Yes (3-5 days per week) & $39(31.20)$ & $3(20.00)$ & $36(32.73)$ \\
\hline \multicolumn{4}{|l|}{ Households } \\
\hline \multicolumn{4}{|l|}{ Bedrooms, No. (\%) } \\
\hline Missing & 9 & & \\
\hline 1 & $4(2.03)$ & $2(8.00)$ & $2(1.16)$ \\
\hline 2 & $47(23.86)$ & $5(20.00)$ & $42(24.42)$ \\
\hline 3 & $86(43.65)$ & $9(36.00)$ & $77(44.77)$ \\
\hline 4 & $42(21.32)$ & $6(24.00)$ & $36(20.93)$ \\
\hline 5 & $14(7.11)$ & $3(12.00)$ & $11(6.40)$ \\
\hline 6 & $3(1.52)$ & $0(0.00)$ & $3(1.74)$ \\
\hline 7 & $0(0.00)$ & $0(0.00)$ & $0(0.00)$ \\
\hline 8 & $1(0.51)$ & $0(0.00)$ & $1(0.58)$ \\
\hline \multicolumn{4}{|l|}{ Resident smoker, No. (\%) } \\
\hline Missing & 9 & & \\
\hline No & $181(91.88)$ & $22(88.00)$ & $159(92.44)$ \\
\hline Yes & $16(8.12)$ & $3(12.00)$ & $13(7.56)$ \\
\hline \multicolumn{4}{|l|}{ Cat/dog in main home, No. (\%) } \\
\hline Missing & 9 & & \\
\hline No & $141(71.57)$ & $16(64.00)$ & $125(72.67)$ \\
\hline Yes & $56(28.43)$ & $9(36.00)$ & $47(27.33)$ \\
\hline \multicolumn{4}{|c|}{ Number of adults resident in child's main home, No. (\%) } \\
\hline Missing & 9 & & \\
\hline 0 & $1(0.51)$ & $0(0.00)$ & $1(0.58)$ \\
\hline 1 & $15(7.61)$ & $2(8.00)$ & $13(7.56)$ \\
\hline 2 & $164(83.25)$ & $20(80.00)$ & $144(83.72)$ \\
\hline 3 & $11(5.58)$ & $0(0.00)$ & $11(6.40)$ \\
\hline 4 & $5(2.54)$ & $3(12.00)$ & $2(1.16)$ \\
\hline 8 & $1(0.51)$ & $0(0.00)$ & $1(0.58)$ \\
\hline \multicolumn{4}{|l|}{ Total number of children in home, No. (\%) } \\
\hline Missing & 9 & & \\
\hline 1 & $80(40.61)$ & $8(32.00)$ & $72(41.86)$ \\
\hline 2 & $103(52.28)$ & $15(60.00)$ & $88(51.16)$ \\
\hline 3 & $12(6.09)$ & $1(4.00)$ & $11(6.40)$ \\
\hline 4 & $1(0.51)$ & $0(0.00)$ & $1(0.58)$ \\
\hline 5 & $0(0.00)$ & $1(4.00)$ & $0(0.00)$ \\
\hline Age of children in home, median (IQR), y & $3(2-7)$ & $2(1-6)$ & $3(2-7)$ \\
\hline \multicolumn{4}{|c|}{$\begin{array}{l}\text { A level = advanced level; } \mathrm{GCE}=\text { general certificate of education; } \mathrm{GCSE}=\text { general certificate of secondary edu- } \\
\text { cation; } \mathrm{GNVQ}=\text { general national vocational qualification; } \mathrm{HNC}=\text { higher national certificate; } \mathrm{HND}=\text { higher } \\
\text { national diploma; } \mathrm{QRR}=\text { interquartile range; } \mathrm{MSc}=\text { master of science; } \mathrm{NVQ}=\text { national vocational qualification; } \mathrm{O} \\
\text { level = general certificate of education ordinary level; } \mathrm{PhD}=\text { doctor of philosophy; } \mathrm{RTI}=\text { respiratory tract infection. }\end{array}$} \\
\hline
\end{tabular}

children (7 days) (Table 3 ). Child's age was not associated with primary care attendance.

\section{Sensitivity Analyses}

Estimates of overall symptom duration were stable when taking account of within-family and within-child clustering. The modest differences in symptom duration observed between children with and without consultations in the main analyses were augmented as a result of within-family (parent) clustering (Table 4).

\section{DISCUSSION}

\section{Summary of Main Results}

In this community-based, online, prospective inception cohort study drawn from 5 GP practices in Bristol, United Kingdom, we showed it takes up to 3 weeks for $90 \%$ of children's RTI symptoms to resolve. There was modest evidence of longer symptom duration for children with consultations vs those without and strong evidence of longer symptom duration in children with lower vs upper RTI symptoms. One in 12 parents sought help from primary care services.

\section{Strengths and Limitations}

To our knowledge, this is the first community-based, inception cohort study to use online methods to measure symptom duration, costs, and primary care help-seeking behavior. This study provides new, relevant knowledge for clinicians and policy makers. Conducting the study in the United Kingdom was ideal since, unlike some health care systems (the United States, for example), we have near-universal population primary care registration. Previous studies have not compared symptom duration in children with and without consultations, and, to our knowledge, no previ- 
Table 2. Duration and Severity of RTI Symptoms, Restricted to First RTI in a Family With Known Illness Start Date $(n=197)$

\begin{tabular}{|c|c|c|c|c|c|c|c|}
\hline \multirow[b]{2}{*}{ Group } & \multirow[b]{2}{*}{ No. } & \multicolumn{5}{|c|}{ RTI Duration by Percentile, d } & \multirow{2}{*}{$\begin{array}{l}P \\
\text { Value }^{\mathrm{a}}\end{array}$} \\
\hline & & $10^{\text {th }}$ & $25^{\text {th }}$ & $50^{\text {th }}$ & $75^{\text {th }}$ & $90^{\text {th }}$ & \\
\hline All children & 197 & 4 & 7 & 9 & 14 & 23 & \\
\hline \multicolumn{8}{|c|}{$\begin{array}{l}\text { Children with and without } \\
\text { consultation }{ }^{\mathrm{b}}\end{array}$} \\
\hline Consultation & 16 & 6 & 9 & 13 & 18 & 37 & \multirow{2}{*}{.06} \\
\hline No consultation & 181 & 4 & 6 & 9 & 13 & 21 & \\
\hline \multicolumn{8}{|c|}{ Upper and lower RTI symptoms, } \\
\hline Exclusively URTI & 86 & 3 & 5 & 8 & 11 & 15 & \multirow[t]{2}{*}{$<.001$} \\
\hline Any LRTI & 104 & 6 & 8 & 12 & 18 & 29.5 & \\
\hline
\end{tabular}

Constitutional symptom severity score ${ }^{\mathrm{e}}$ for upper and lower RTI, mean of maximum

\begin{tabular}{lcc} 
& Upper RTI & Lower RTI \\
\hline Fever & 0.55 & 1.07 \\
Fatigue & 0.83 & 1.71 \\
Disruption to sleep & 1.15 & 2.19 \\
Disruption to other activities & 0.67 & 1.43 \\
\hline
\end{tabular}

LRTI = lower respiratory tract infection; NHS = National Health Service; RTI = respiratory tract infection; URTI = upper respiratory tract infection.

a Log-rank test for difference between episodes with consultions and those without consultions.

${ }^{\mathrm{b}}$ Any NHS primary care attendance according to medical notes.

' 7 RTI episodes which did not report any URTI- or LRTI-defining symptoms.

' URTI symptoms: earache, sore throat, runny/blocked nose, ear discharge, dry cough or barking/croupy cough.

LRTI symptoms: wet/productive cough, breathing faster/shortness of breath, or wheeze/whistling chest.

e Maximum of daily scores in first 21 days, based on Likert scale 0 (normal, no problem) to 6 (as bad as it could be).

Figure 2. Kaplan-Meier curve showing time to RTI symptom resolution (with number censored), restricted to the first RTI in a family with illness start date recorded $(n=197)$.

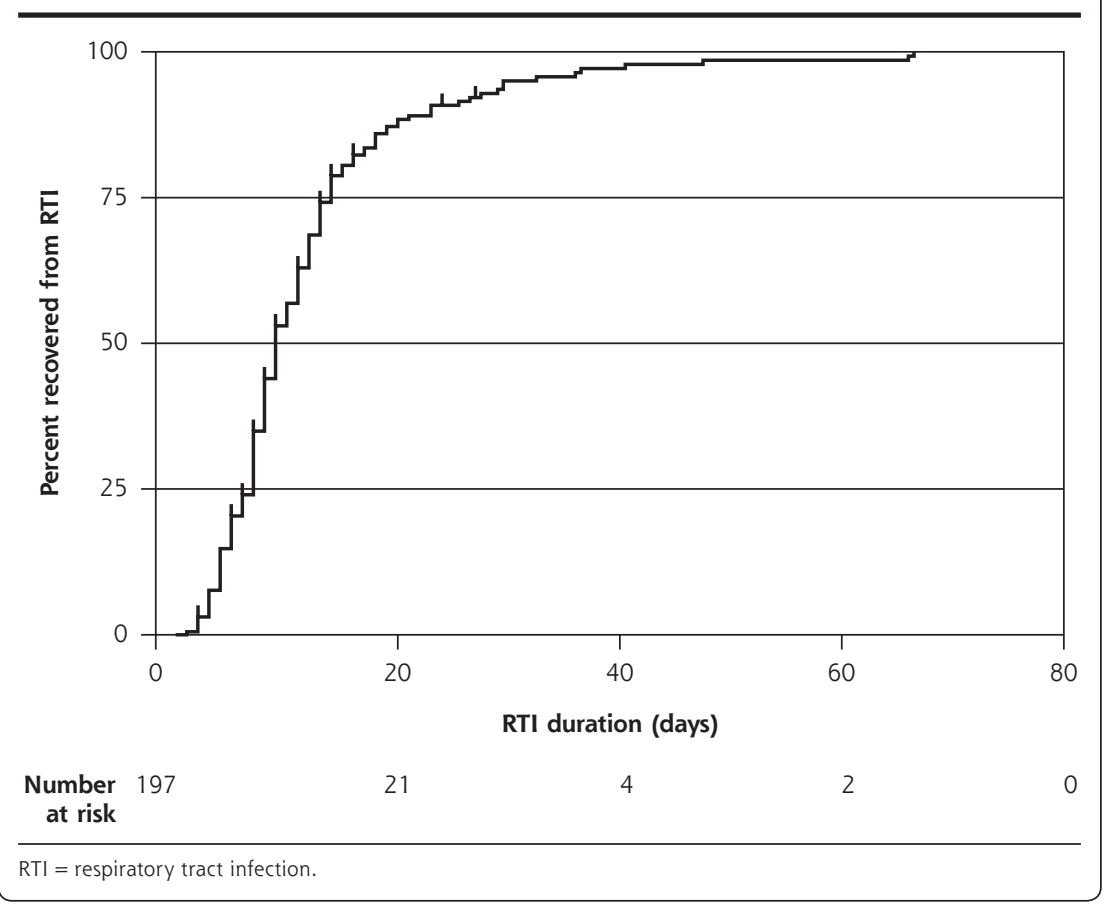

ous study has demonstrated the prognostic value of parentreported lower RTI symptoms.

We are aware of several limitations. First, the initial invitation response rate was low, although our study response rate was nearly double that of another study using similar methods. ${ }^{15}$ Responding parents had younger children and were less socioeconomically deprived than nonresponding parents, but our consultation rate estimate was not univariably associated with deprivation and age. Twenty percent of parents reported medical or nursing training, suggesting families with higher medical knowledge than the general population were recruited. Second, our observation period was relatively short and included some summer months. This limited our ability to investigate seasonal variation and likely resulted in the inclusion of allergic conditions. Third, we did not achieve the expected sample size. Although the precision of our symptom duration and consultation rate estimates were not materially affected, this prevented us from using hierarchical modeling to control for clustering by recruitment practice and meant we had insufficient numbers to conduct the multivariable modeling that would be required to robustly confirm the effect of maternal deprivation and education on symptom duration and consultation. Fourth, symptom duration estimates could have been influenced by: (1) younger children with longer illnesses who were more likely to participate in the study (leading to an overestimation of symptom duration); (2) parents might have tired of completing symptom diaries for longer illnesses (underestimation); and (3) our analyses presented 
Table 3. Effect of Deprivation/Baseline Characteristics on RTI Symptom Duration and Consultations, Restricted to First RTI in a Family With Illness Start Date $(n=197)$

\begin{tabular}{|c|c|c|c|c|c|}
\hline Characteristic & No. & $\begin{array}{c}\text { Consultation, } \\
\text { No. (\%) }\end{array}$ & $\begin{array}{c}P \\
\text { Value }\end{array}$ & $\begin{array}{l}\text { Median } \\
\text { Duration, d }\end{array}$ & $\begin{array}{c}P \\
\text { Value }\end{array}$ \\
\hline \multicolumn{6}{|l|}{ Parent education level } \\
\hline No official qualification & 2 & $0(0.0)$ & \multirow{6}{*}{.93} & 1 & \multirow{6}{*}{.09} \\
\hline GCSE/GCE/O level & 6 & $0(0.0)$ & & 14 & \\
\hline A level/NVQ/GNVQ & 9 & $1(11.1)$ & & 7 & \\
\hline $\begin{array}{l}\text { First degree (diploma/ } \\
\text { HNC/HND) }\end{array}$ & 105 & $9(8.6)$ & & 10 & \\
\hline Higher degree (MSc/PhD) & 67 & $5(7.5)$ & & 9 & \\
\hline Missing & 8 & $1(12.5)$ & & 7 & \\
\hline \multicolumn{6}{|l|}{ Age of child } \\
\hline$\geq 3$ years & 106 & $9(8.5)$ & \multirow[t]{3}{*}{.87} & 11 & \multirow[t]{3}{*}{$<.01$} \\
\hline$>3$ years & 91 & $7(7.7)$ & & 7 & \\
\hline Missing & 0 & $0(0.0)$ & & 0 & \\
\hline \multicolumn{6}{|l|}{$\begin{array}{l}\text { Household Index of } \\
\text { Multiple Deprivation }\end{array}$} \\
\hline 1 (most deprived) & 74 & $5(6.8)$ & \multirow{4}{*}{.83} & 9 & \multirow{4}{*}{.79} \\
\hline 2 & 57 & $5(8.8)$ & & 9 & \\
\hline 3 (least deprived) & 63 & $6(9.5)$ & & 9 & \\
\hline Missing & 3 & $0(0.0)$ & & 23 & \\
\hline \multicolumn{6}{|c|}{$\begin{array}{l}\text { A level = advanced level; } \mathrm{GCE}=\text { general certificate of education; } \mathrm{GCSE}=\text { general certificate of secondary edu- } \\
\text { cation; } \mathrm{GNVQ}=\text { general national vocational qualification; } \mathrm{HNC}=\text { higher national certificate; } \mathrm{HND}=\text { higher } \\
\text { national diploma; } \mathrm{MSC}=\text { master of science; } \mathrm{NVQ}=\text { national vocational qualification; } \mathrm{O} \text { level = general certificate } \\
\text { of education ordinary level; } \mathrm{PhD}=\text { doctor of philosophy; } \mathrm{RTI}=\text { respiratory tract infection. }\end{array}$} \\
\hline
\end{tabular}

ideally, also providing information to parents about which symptoms are cause for seeking consultation. Similarly, such interventions could advise parents to expect longer and more severe illnesses if children have lower respiratory symptoms. Clinicians conducting telephone triage could also provide additional reassurance to parents reporting exclusively upper respiratory symptoms.

Although the $8 \%$ consultation rate could be an underestimate, it suggests there is a significant illness iceberg. Policy makers, clinicians, and directors of public health need to be mindful of unintentionally lowering the consultation threshold and increasing the percentage of parents consulting.

Future studies should be larger, to provide for use of multivariable modeling to identify the social, psychological, and clinical factors ${ }^{17}$ associated with

all respiratory symptoms combined, with shorter symptoms hidden by longer symptoms (overestimation). Fifth, among those with no new respiratory symptoms reported, we are unable to distinguish between parents not responding, and those responding with no new symptoms. Finally, the consultation rate may be an underestimate since ours was a relatively medically aware, affluent population, and previous research ${ }^{16}$ has suggested consultation rates are likely to be higher in less-affluent families.

\section{Comparison With Existing Literature}

The time for both longer (such as cough) and shorter (ear pain) duration symptoms were similar to those observed in our 2013 systematic review. ${ }^{5}$ There is very little evidence with which to compare pediatric consultation rates.

\section{Implications for Public Health, Clinical Practice, and Research}

Knowledge of RTI symptom duration in a nonconsulting population could inform GP practice/public health interventions by helping parents to know how long to expect respiratory symptoms to last. And consulting, and to confirm the modest evidence of shorter illnesses in children without consultations. Additional studies should also monitor illnesses over longer time periods, in order to understand seasonal
Table 4. Sensitivity Analyses for Overall RTI Duration and Duration Stratified by Child's Consultation Attendance ${ }^{a}$

\begin{tabular}{|c|c|c|c|c|c|c|c|}
\hline \multirow[b]{2}{*}{ Group } & \multirow[b]{2}{*}{ No. } & \multicolumn{5}{|c|}{ RTI Duration by Percentile, d } & \multirow{2}{*}{$\begin{array}{c}P \\
\text { Value }^{b}\end{array}$} \\
\hline & & $10^{\text {th }}$ & $25^{\text {th }}$ & $50^{\text {th }}$ & $75^{\text {th }}$ & $90^{\text {th }}$ & \\
\hline \multicolumn{8}{|c|}{ Primary comparison (reference Table 2 ) } \\
\hline \multicolumn{8}{|l|}{ First RTI in a family } \\
\hline All & 197 & 4 & 7 & 9 & 14 & 23 & \multirow{3}{*}{.06} \\
\hline Consultation & 16 & 6 & 9 & 13 & 18 & 37 & \\
\hline Non Consultation & 181 & 4 & 6 & 9 & 13 & 21 & \\
\hline \multicolumn{8}{|l|}{ Sensitivity analyses } \\
\hline \multicolumn{8}{|l|}{ First RTI in a child } \\
\hline All & 246 & 4 & 7 & 9 & 14 & 23 & \multirow{3}{*}{.05} \\
\hline Consultation & 18 & 6 & 11 & 13 & 18 & 37 & \\
\hline Non Consultation & 228 & 4 & 6 & 9 & 14 & 21 & \\
\hline \multicolumn{8}{|l|}{ All RTIs } \\
\hline All & 338 & 4 & 7 & 10 & 15 & 26 & \multirow{3}{*}{$<.01$} \\
\hline Consultation & 34 & 8 & 13 & 14 & 27 & 28 & \\
\hline Non Consultation & 304 & 4 & 6 & 9 & 14 & 21 & \\
\hline
\end{tabular}


variation. Future research should also measure and report individual symptom duration in more detail, and comparative studies are needed in different countries and health care settings.

\section{CONCLUSIONS}

Parents can be advised that RTI symptoms in children can last up to 3 weeks. Policy makers should be aware that parents may seek primary care support in at least 1 in 12 illnesses.

\section{To read or post commentaries in response to this article, see it} online at http://www.AnnFamMed.org/content/17/1/14.

Key words: child; respiratory tract infections; primary health care; antibacterial agents

Submitted March 20, 2018; submitted, revised, August 9, 2018; accepted September 27, 2018.

Authors' contributions: A.D.H. and W.H. were responsible for developing the research question, securing funding, and the study design. All authors were responsible for data collection. E.A. and A.D.H. were responsible for study management and coordination. S.I. and W.H. were responsible for data analysis. A.D.H., E.A., S.I., and W.H. drafted the paper. All authors have commented on and approved the final manuscript.

Funding support: This study was partly supported by the NIHR Health Protection Research Unit in Evaluation of Interventions at University of Bristol. The views expressed are those of the author(s) and not necessarily those of the NHS, the NIHR, the Department of Health, or Public Health England. The Bristol Randomized Trials Collaboration (BRTC) has contributed funding and input into study outputs via development work on the database system used to coordinate the study and collect data from participants. A.D.H. was funded by NIHR Research Professorship (NIHR-RP-02-12-012).

The South West Frenchay Bristol Research Ethics Committee approved the study (reference: 15/SW/0264), and research governance approvals were obtained before recruitment. All participants' parent or legal caregivers gave written, informed consent on behalf of the child. All children aged 7 years by September 2015 (equivalent of school year 3) and over gave informed assent. The study was sponsored by the University of Bristol, which ensured the study met all regulatory approvals.

Disclaimer: A.D.H. (corresponding and guarantor author) affirms that the manuscript is an honest, accurate, and transparent account of the study being reported; that no important aspects of the study have been omitted; and that any discrepancies from the study as planned (and, if relevant, registered) have been explained.

Acknowledgments: The authors are extremely grateful to the children and parents/caregivers who have participated in the study; all GP practices including clinicians, administrative, and research contacts; and the NIHR Clinical Research Network, West of England (study registration number 19814) whose help made this study possible. We also wish to thank our study research nurses and the Study Management Group for their time, expertise, and support.

Supplemental Materials: Available at http://www.AnnFamMed. org/content/17/1/14/suppl/DC1/.

\section{References}

1. NHS England. NHS General Practice Forward View. https://www. england.nhs.uk/wp-content/uploads/2016/04/gpfv.pdf. Published Apr 2016.

2. Britain Self Care Forum, PAGB. Self care: the first step to saving the NHS. http://www.selfcareforum.org/wp-content/uploads/2013/12/ SelfCareConferencereport2013.pdf. Published 2013.

3. Pencheon D. Matching demand and supply fairly and efficiently. BMJ. 1998;316(7145):1665-1667.

4. Macfarlane JT, Holmes WF, Macfarlane RM. Reducing reconsultations for acute lower respiratory tract illness with an information leaflet: a randomized controlled study of patients in primary care. Br J Gen Pract. 1997:47(424):719-722.

5. Thompson M, Vodicka TA, Blair PS, Buckley DI, Heneghan C, Hay AD; TARGET Programme Team. Duration of symptoms of respiratory tract infections in children: systematic review. BMJ. 2013;347: f7027. 10.1136/bmj.f7027.

6. Public Health England. English surveillance programme for antimicrobial utilisation and resistance (ESPAUR) 2010 to 2014. Report 2015. https://assets. publishing.service.gov.uk/government/ uploads/system/uploads/attachment_data/file/477962/ESPAUR_ Report_2015.pdf. Published Nov 2015.

7. Ashworth M, Charlton J, Latinovic R, Gulliford M. Age-related changes in consultations and antibiotic prescribing for acute respiratory infections, 1995-2000. Data from the UK General Practice Research Database. J Clin Pharm Ther. 2006;31(5):461-467. 10.1111/j.1365-2710.2006.00765.x.

8. Hollinghurst S, Gorst C, Fahey T, Hay AD. Measuring the financial burden of acute cough in pre-school children: a cost of illness study. BMC Fam Pract. 2008;9(1):10. 10.1186/1471-2296-9-10.

9. Anderson EC, Ingle SM, Muir P, et al. Community paediatric respiratory infection surveillance study protocol: a feasibility, prospective inception cohort study. BMJ Open. 2016;6(8):e013017. 10.1136/ bmjopen-2016-013017.

10. Watson L, Little P, Moore M, et al. Validation study of a diary for use in acute lower respiratory tract infection. Fam Pract. 2001;18(5): 553-54.

11. McNulty CA, Nichols T, French DP, Joshi P, Butler CC. Expectations for consultations and antibiotics for respiratory tract infection in primary care: the RTI clinical iceberg. Br J Gen Pract. 2013;63(612): e429-e436. 10.3399/bjgp13X669149.

12. Hay AD, Wilson A, Fahey T, Peters TJ. The duration of acute cough in pre-school children presenting to primary care: a prospective cohort study. Fam Pract. 2003;20(6):696-705. 10.1093/fampra/ cmg613.

13. Anderson EC, Ingle $S$, Muir $P$, et al. Population-based paediatric respiratory infection surveillance: a prospective inception feasibility cohort study. BMC Pilot and Feasibility Studies 2018;4(1):182.

14. Department of Environment, Transport, and the Regions. Indices of Deprivation 2000. http://webarchive.nationalarchives.gov. uk/+/http:/www.communities.gov.uk/documents/citiesandregions/ pdf/131306.pdf. Published Aug 2000.

15. Little P, Stuart B, Hobbs FD, et al. An internet-delivered handwashing intervention to modify influenza-like illness and respiratory infection transmission (PRIMIT): a primary care randomised trial. Lancet. 2015;386(10004):1631-1639. 10.1016/\$0140-6736(15)60127-1.

16. Little $\mathrm{P}$, Somerville J, Williamson I, et al. Family influences in a cross-sectional survey of higher child attendance. $\mathrm{Br} J$ Gen Pract. 2001;51(473):977-981, 984.

17. Wyke S, Hewison J, Russell IT. Respiratory illness in children: what makes parents decide to consult? Br J Gen Pract. 1990;40(335): 226-229. 